\title{
How Long Does Antimycobacterial Antibiotic-loaded Bone Cement Have In Vitro Activity for Musculoskeletal Tuberculosis?
}

\author{
Jae Hoo Lee MD, Chang Dong Han MD, PhD, Sang-Nae Cho DVM, PhD, Ick Hwan Yang MD, PhD, \\ Woo Suk Lee MD, PhD, Seung-Hun Baek PhD, Jae Won Shin MD, Khalid Elfadil Ibrahim Husein MD, \\ Kwan Kyu Park MD, PhD
}

Received: 6 April 2017/ Accepted: 2 August 2017/Published online: 9 August 2017

(C) The Association of Bone and Joint Surgeons \& 2017

\begin{abstract}
Background Antibiotic-loaded bone cement is accepted as an effective treatment modality for musculoskeletal tuberculosis. However, comparative information regarding combinations and concentrations of second-line antimycobacterial drugs, such as streptomycin and amoxicillin and clavulanic acid, are lacking.

Questions/Purposes (1) In antibiotic-loaded cement, is there effective elution of streptomycin and Augmentin ${ }^{\circledR}$

This study was supported by a faculty research grant from Yonsei University College of Medicine (6-2015-0060).

All ICMJE Conflict of Interest Forms for authors and Clinical Orthopaedics and Related Research ${ }^{(\mathbb{R}}$ editors and board members are on file with the publication and can be viewed on request. Clinical Orthopaedics and Related Research ${ }^{\circledR}$ neither advocates nor endorses the use of any treatment, drug, or device. Readers are encouraged to always seek additional information, including FDAapproval status, of any drug or device prior to clinical use.

This work was done at the Department of Orthopaedic Surgery, Yonsei University College of Medicine, Seoul, Korea.
\end{abstract}

J. H. Lee, I. H. Yang, W. S. Lee, J. W. Shin, K. K. Park (凹) Department of Orthopaedic Surgery, Yonsei University College of Medicine, 134 Sinchon-dong, Seodaemun-gu, Seoul 120-752, Korea

e-mail: kkpark@yuhs.ac

S.-N. Cho, S.-H. Baek

Department of Microbiology and Institute for Immunology and Immunological Diseases, Yonsei University College of

Medicine, Seoul, Korea

C. D. Han

Department of Orthopaedic Surgery, Seoul Bumin Hospital, Seoul, Korea

K. E. I. Husein

Department of Trauma and Orthopaedic Surgery, Kosti Teaching Hospital, Kosti, Sudan (amoxicillin and clavulanic acid) individually and in combination? (2) What is the antibacterial activity duration for streptomycin- and amoxicillin and clavulanic acid loaded cement?

Methods Six different types of bone cement discs were created by mixing $40 \mathrm{~g}$ bone cement with 1 or $2 \mathrm{~g}$ streptomycin only, $0.6 \mathrm{~g}$ or $1.2 \mathrm{~g}$ Augmentin ${ }^{\circledR}$ (amoxicillin and clavulanic acid) only, and a combination of $1 \mathrm{~g}$ streptomycin plus $0.6 \mathrm{~g}$ amoxicillin and clavulanic acid and $2 \mathrm{~g}$ streptomycin plus $1.2 \mathrm{~g}$ amoxicillin and clavulanic acid. Five bone discs of each type were incubated in phosphate buffered saline for 30 days with renewal of the phosphate buffered saline every day. The quantity of streptomycin and/or amoxicillin and clavulanic acid in eluates were measured by a liquid chromatography-mass spectrometry system, and the antimycobacterial activity of eluates against Mycobacterium tuberculosis H37Rv, were calculated by comparing the minimal inhibitory concentration of each eluate with that of tested drugs using broth dilution assay on microplate.

Results Streptomycin was detected in eluates for 30 days (in $1 \mathrm{~g}$ and $2 \mathrm{~g}$ discs), whereas $1.2 \mathrm{~g}$ amoxicillin and clavulanate eluted until Day 7 and $0.6 \mathrm{~g}$ amoxicillin and clavulanate until Day 3. All eluates in streptomycin-containing discs (streptomycin only, and in combination with amoxicillin and clavulanic acid) had effective antimycobacterial activity for 30 days, while amoxicillin and clavulanate-only preparations were only active until Day 14. The antimycobacterial activity of eluates of $2 \mathrm{~g}$ streptomycin plus $1.2 \mathrm{~g}$ amoxicillin and clavulanate were higher than those of discs containing $1 \mathrm{~g}$ streptomycin plus $0.6 \mathrm{~g}$ amoxicillin and clavulanate until Day 3, without differences (Day 3, $1 \mathrm{~g}$ streptomycin plus $0.6 \mathrm{~g}$ amoxicillin and clavulanate: $17.5 \pm 6.85 \mathrm{ug} / \mathrm{mL} ; 2 \mathrm{~g}$ streptomycin plus 1.2 $\mathrm{g}$ amoxicillin and clavulanate: $32.5 \pm 16.77 \mathrm{ug} / \mathrm{mL} ; \mathrm{p}=$ 
0.109). After Day 7, however, values of the two combinations remained no different than that of Day 30 (Day 30, $1 \mathrm{~g}$ streptomycin plus $0.6 \mathrm{~g}$ amoxicillin and clavulanate: $0.88 \pm 0.34 \mathrm{ug} / \mathrm{mL} ; 2 \mathrm{~g}$ streptomycin plus $1.2 \mathrm{~g}$ amoxicillin and clavulanate: $0.59 \pm 0.94 \mathrm{ug} / \mathrm{mL} ; \mathrm{p}=0.107$ ).

Conclusions Streptomycin, in the form of antibioticloaded bone cement, had effective elution characteristics and antimycobacterial effects during a 30-day period, whereas amoxicillin and clavulanate only had effective elution and antimycobacterial characteristics during the early period of this study. The two drugs did not interfere with each other during the elution test.

Clinical Relevance This research revealed that combinations of streptomycin and amoxicillin and clavulanate mixed with bone cement are effective for 30 days. Further trials to determine various different combinations of drugs are necessary to improve the effectiveness of treatments for musculoskeletal tuberculosis.

\section{Introduction}

Musculoskeletal tuberculosis requires appropriate surgical treatment according to the location and degree of destruction [8, 9, 15, 44]. Insertion of antibiotic-loaded bone cement along with débridement are initial surgical treatment options for pyogenic or tuberculosis bone or joint infections to control active infection before further treatments such as arthrodesis, resection arthroplasty, or prosthetic replacement $[25,32,42]$. Some studies have shown the effectiveness of antibiotic-loaded bone cement in pyogenic osteomyelitis $[14,29,40,45]$, while other studies have shown the effectiveness of antibiotic-loaded bone cement in tuberculosis osteomyelitis or arthritis $[20,25,32,42]$. Furthermore, there is little information regarding combinations of antibiotics or their mixture ratios with bone cement $[23,30,31,38]$.

We previously performed an in vitro study of isoniazidand rifampicin-loaded bone cement to investigate the elution characteristics and antibacterial activity of this cement [20]. We found that isoniazid had an antimycobacterial effect when incorporated in bone cement, while rifampicin was not suitable for creating antibioticloaded bone cement owing to delayed polymerization. However, no powder form of isoniazid is currently available, which limits the practical application of this antibiotic. Therefore, we designed this followup study to identify drugs that surgeons can use to treat musculoskeletal tuberculosis. Among second-line drugs of the aminoglycoside family, kanamycin and streptomycin are available in powder forms. After several preliminary experiments, we decided to further evaluate the second- line drugs streptomycin and Augmentin ${ }^{\circledR}$ (amoxicillin and clavulanic acid).

Therefore, we asked the following questions: (1) In antibiotic-loaded cement, is there effective elution of streptomycin and amoxicillin and clavulanic acid individually and in combination? (2) What is the antibacterial activity duration for streptomycin- and amoxicillin clavulanic acid -loaded cement?

\section{Materials and Methods}

Six different combinations of antibiotics were mixed with $40 \mathrm{~g}$ customized bone cement powder containing $1 \mathrm{~g}$ gentamicin $\left(\mathrm{CMW}^{\mathrm{TM}} 3\right.$; DePuy-Synthes, Warsaw, IN, USA) (Fig. 1). The six different combinations were as follows: $1 \mathrm{~g}$ or $2 \mathrm{~g}$ of streptomycin only (North China Pharmaceutical Huasheng Co, Ltd, Shijiazhuang, China); $0.6 \mathrm{~g}$ or $1.2 \mathrm{~g}$ of Augmentin ${ }^{\circledR}$ (amoxicillin and clavulanate) only (Augmentin ${ }^{\circledR}$ GSK, Glaxosmithkline, Brentford, $\mathrm{UK}$ ); combinations of $1 \mathrm{~g}$ streptomycin plus $0.6 \mathrm{~g}$ amoxicillin and clavulanate, and $2 \mathrm{~g}$ streptomycin plus $1.2 \mathrm{~g}$ amoxicillin and clavulanate. Antibiotic-loaded bone cement was made under sterile conditions in the operating room. To make it as porous as possible to increase the spread of the antibiotic, the powder mixture was mixed by hand for 2 minutes after liquid monomer was added. For each of the six combinations of antibiotic-loaded bone cement powder, five discs for each of the elution characteristics or the antibacterial activity test were made to obtain result consistency. The discs were made in premade cylindrical molds and were $10 \pm 0.8 \mathrm{~mm}$ in diameter and $50 \pm 1.2 \mathrm{~mm}$ in height, with a weight of $4.4 \pm 0.26 \mathrm{~g}$. When creating antibiotic-loaded bone cements containing amoxicillin and clavulanate, polymerization was delayed; a claylike texture persisted until the bone cement hardened after a mean of $122.5 \pm 31.1$ minutes. Each antibioticloaded bone cement disc was immersed in a $50-\mathrm{mL}$ test tube that was protected from light and contained $40 \mathrm{~mL}$ phosphate buffered saline (PBS). The test tubes were kept at $37^{\circ} \mathrm{C}$. PBS was replaced daily at a sterile bench. One milliliter of eluate was taken to measure elution characteristics and $1 \mathrm{~mL}$ was taken to assess antimycobacterial activity on Days 1, 4, 7, 14, and 30, just before exchanging the PBS. A total of 300 samples (150 samples to determine elution characteristics and 150 samples to determine antimycobacterial activity) were obtained. All samples were frozen at $-20^{\circ} \mathrm{C}$ until measurement.

The amount of antibiotic in the eluate was quantified using a liquid chromatography-mass spectrometry system. High-performance liquid chromatography (Agilent 1100 series; Agilent Technologies, Santa Clara, CA, USA) was used to segregate compounds detected with the mass 


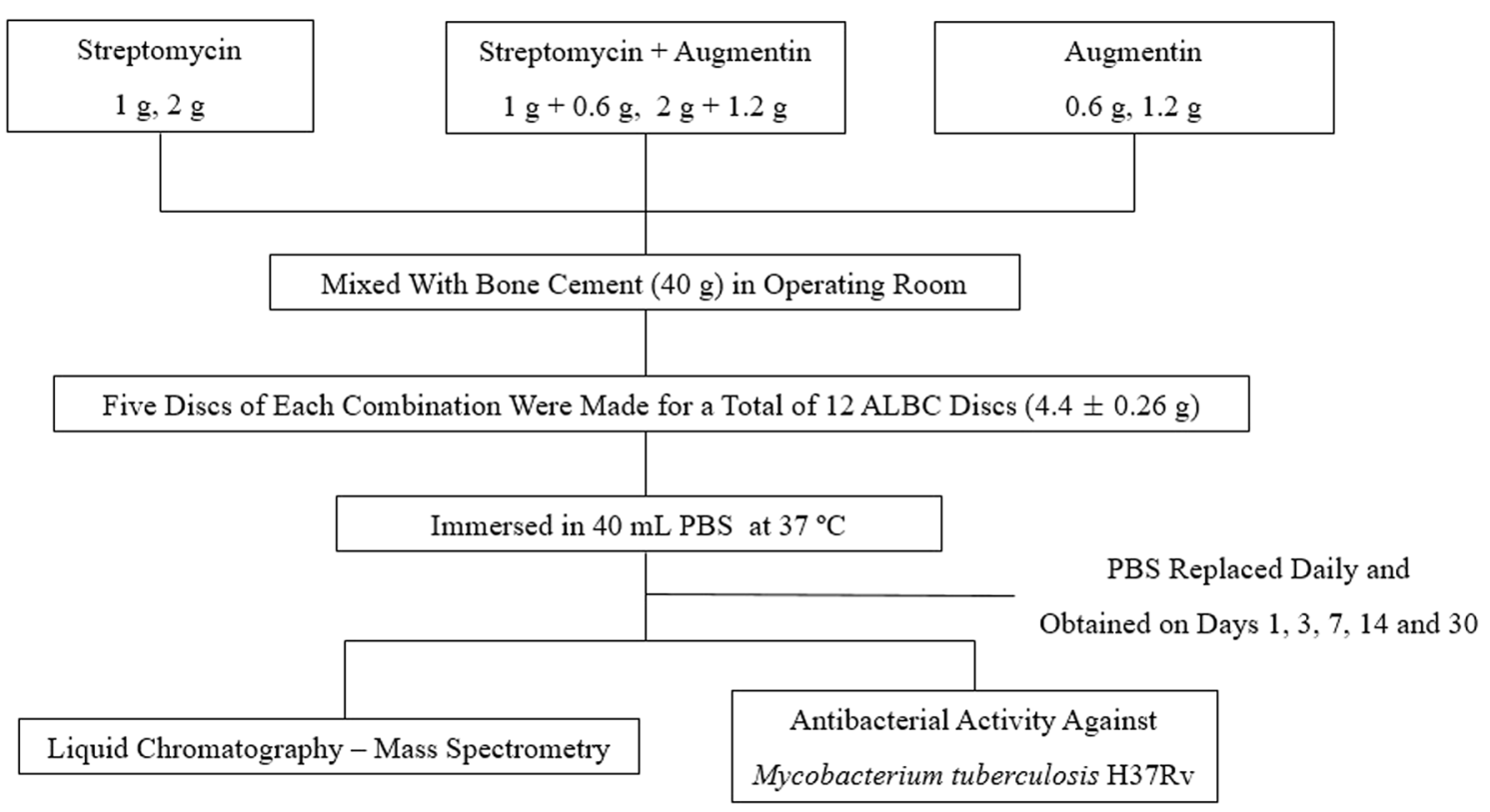

Fig. 1 The study flow design is shown. ALBC = antibiotic-loaded bone cement; PBS = phosphate buffered saline.

spectrometer (API3200 ${ }^{\mathrm{TM}}$; AB SCIEX, Framingham, MA, USA). For the high-performance liquid chromatography, $0.1 \%$ formic acid: acetonitrile $(80: 20[\mathrm{v} / \mathrm{v}])$ was used as the mobile phase, and Kinetex ${ }^{\circledR} \mathrm{C} 18(2.6 \mu \mathrm{m}, 4.6 \mathrm{~mm} \times 50$ $\mathrm{mm}$; Phenomenex, Torrance, CA, USA) was used as the column. We used the positive ion mode for streptomycin, and the negative ion mode for amoxicillin and clavulanic acid. The scan mode was the multiple reaction monitoring mode.

To measure antimycobacterial activity, a microplate assay was performed using Mycobacterium tuberculosis (Mtb) H37Rv expressing green fluorescent protein [12]. Mtb H37Rv-green fluorescent protein was grown in $10 \mathrm{~mL}$ of Middlebrook 7H9 broth (Difco Laboratories Inc, Sparks, MD, USA) supplemented with $50 \mathrm{mg} / \mathrm{L}$ kanamycin, $0.2 \%$ (v/v) glycerol (Sigma-Aldrich, St Louis, MO, USA), $1.0 \mathrm{~g}$ casitone (Difco Laboratories Inc) per liter, 10\% (v/v) oleic acid, albumin, dextrose, and catalase (OADC; Difco Laboratories Inc), and $0.05 \%$ (v/v) Tween ${ }^{\mathbb{R}} 80$ (SigmaAldrich) until its optical density at $600 \mathrm{~nm}$ reached 0.4 . The minimal inhibitory concentration of eluent was determined using broth dilution assay on the microplate. The first dilution in the microplate wells of each eluent led to $2.5 \%$, $5 \%, 10 \%, 25 \%, 50 \%$, and $75 \%$, respectively, of each eluent, and then twofold serial dilutions of each concentration of the initial dilutions were made in $7 \mathrm{H} 9$ broth in the microplate. Twofold serial dilutions of all eluates were made in $7 \mathrm{H} 9$ broth in the microplates. Each plate well was inoculated with $\mathrm{H} 37 \mathrm{Rv}$-green fluorescent protein at $2 \times$ $10^{5} \mathrm{CFU} / \mathrm{mL}$. Plates containing eluate dilutions and Mtb were incubated at $37^{\circ} \mathrm{C}$ for 7 days, after which fluorescence was measured in a FLUOstar ${ }^{\circledR}$ OPTIMA (BMG LABTECH GmbH, Ortenberg, Germany) microplate fluorometer using a bottom-reading mode with excitation at $485 \mathrm{~nm}$ and emission at $520 \mathrm{~nm}$.

The minimal inhibitory concentration (MIC) was defined as the lowest concentration of antibiotic(s) in the eluate that inhibited fluorescence by $90 \%$ compared with the fluorescence of bacteria-only wells. The MICs of the tested antibiotics, of which stock was prepared at $10 \mathrm{mg} / \mathrm{mL}$ in dimethyl sulfoxide, were measured at the same time. Antimycobacterial concentration of each antibiotic in each eluent was calculated by comparing the MIC of each eluent with that of the tested antibiotic, assuming obtained MICs of eluent should contain MICs of tested antibiotic: antimycobacterial concentration = $($ MIC of tested drug $\times 100) /$ concentration $(\%)$ of eluent at MIC.

Antimycobacterial concentration of each antibiotic in each eluate was calculated by comparing the MIC of each eluate with that of the tested drugs. The mean MIC values that were experimentally measured for streptomycin, amoxicillin and clavulanate, and streptomycin plus amoxicillin and clavulanate were $0.156,2.5$, and $0.313 \mathrm{mg} / \mathrm{L}$, respectively. Antimycobacterial activity against Mtb was considered effective when the concentration of antibiotics was greater than the mean MIC value [13].

SPSS Statistics for Windows Version 23.0 (IBM Corporation, Armonk, NY, USA) and a probability less than 0.05 indicated statistical significance, with $95 \%$ CI. Descriptive evaluation was performed based on the mean values and standard deviations. Paired t-test was used to 
Fig. 2 The graph shows elution of $1 \mathrm{~g}$ and $2 \mathrm{~g}$ Streptomycin mixed with $40 \mathrm{~g}$ customized bone cement with time. The broken line indicates elution of $1 \mathrm{~g}$ streptomycin, and the solid line indicates elution of $2 \mathrm{~g}$ streptomycin. The concentration of elution of $2 \mathrm{~g}$ streptomycin has been higher than that of $1 \mathrm{~g}$ streptomycin throughout the entire period of experiment.
Elution for Streptomycin

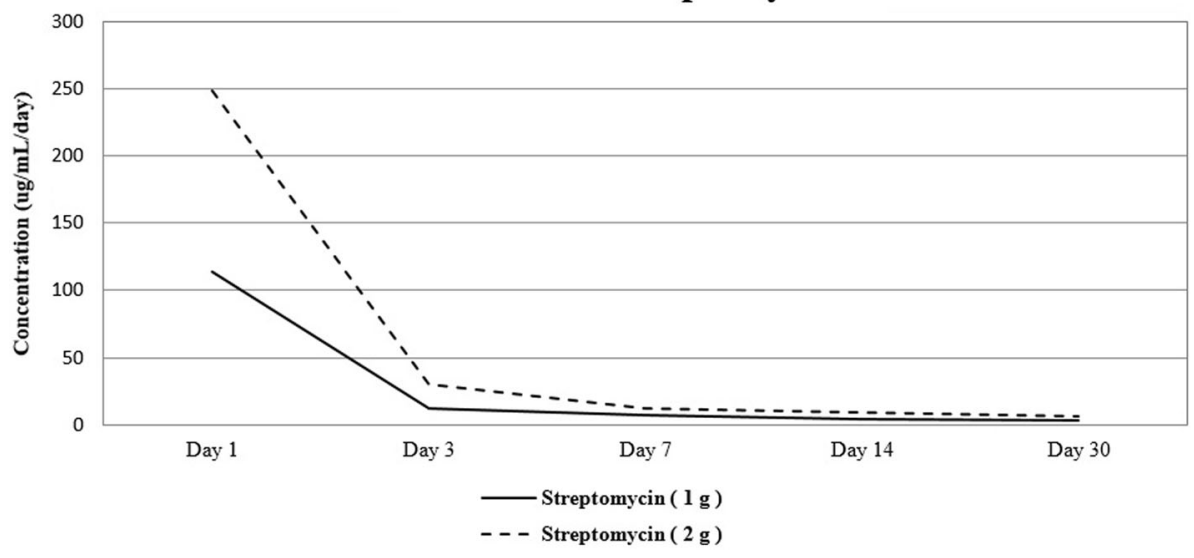

Elution for Streptomycin

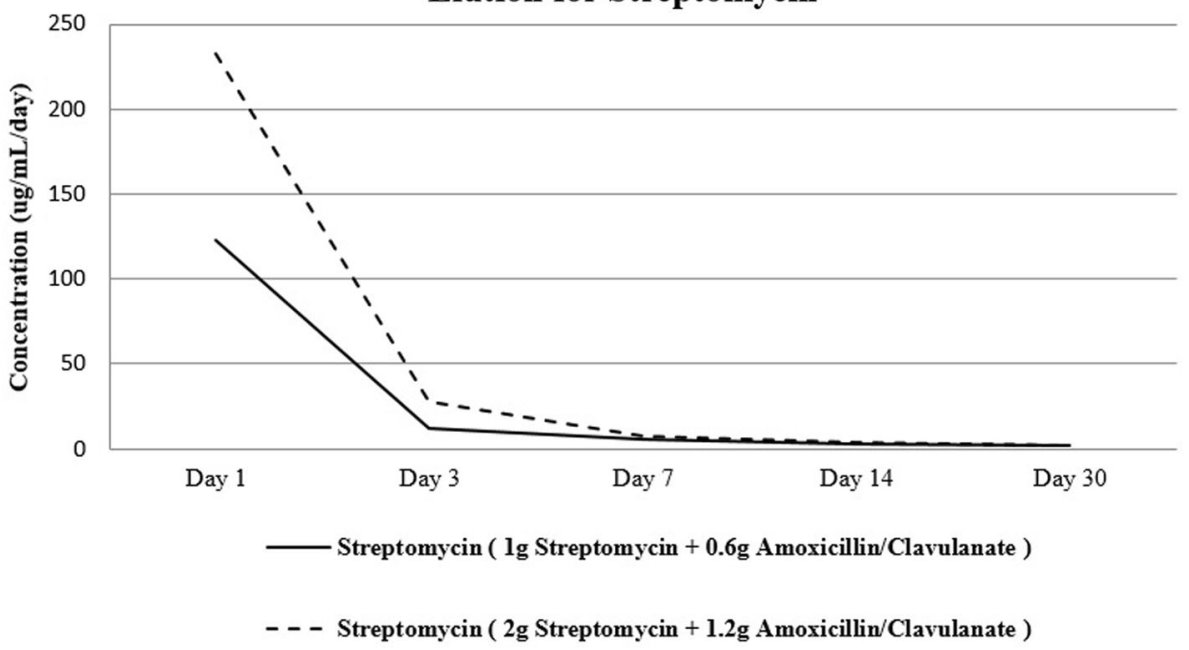

Fig. 3 The graph shows elution of $1 \mathrm{~g}$ streptomycin plus $0.6 \mathrm{~g}$ amoxicillin and clavulanate, and $2 \mathrm{~g}$ streptomycin plus $1.2 \mathrm{~g}$ amoxicillin and clavulanate mixed with $40 \mathrm{~g}$ customized bone cement with time. The solid line indicates elution of $1 \mathrm{~g}$ streptomycin plus $0.6 \mathrm{~g}$ amoxicillin and clavulanate, and the broken line indicates

compare the sample values from five discs for each elution and antimycobacterial tests.

\section{Results}

Streptomycin was detected in eluates sampled at all times up to 30 days (Figs. 2, 3), but amoxicillin and clavulanate was detected only up to 1 week (Fig. 4) (Table 1). Amoxicillin was detected until Day 3 in samples containing $0.6 \mathrm{~g}$ amoxicillin and clavulanate and until Day 7 in samples containing $1.2 \mathrm{~g}$ amoxicillin and clavulanate (Fig. 5). However, clavulanic acid was detected only on Day 1 in eluates from amoxicillin and clavulanate- elution of $2 \mathrm{~g}$ streptomycin plus $1.2 \mathrm{~g}$ amoxicillin and clavulanate. The concentration of elution of $2 \mathrm{~g}$ streptomycin plus $1.2 \mathrm{~g}$ amoxicillin and clavulanate remained higher than that of $1 \mathrm{~g}$ streptomycin plus $0.6 \mathrm{~g}$ amoxicillin and clavulanate throughout the entire period of experiment.

containing samples. The same finding described above was observed for antibiotic-loaded bone cement discs containing streptomycin and amoxicillin and clavulanic acid, with the concentration of amoxicillin undetectable after Day 3. Concentrations of antibiotics decreased with time. The concentration of streptomycin at Day 3 was approximately $10 \%$ of that on Day 1 (Table 1). However, regardless of mixture concentrations, there was no difference in elution amount at Day 30 (1 g streptomycin plus $0.6 \mathrm{~g}$ amoxicillin and clavulanate: 1.86 $\pm 0.58 \mu \mathrm{g} / \mathrm{mL} ; 2 \mathrm{~g}$ streptomycin plus $1.2 \mathrm{~g}$ amoxicillin and clavulanate $1.72 \pm 0.80 \mathrm{ug}$ and $\mathrm{mL}, 95 \% \mathrm{CI}$ of the difference; lower $=-0.27 \mu \mathrm{g} / \mathrm{mL}$, upper $=0.55 \mu \mathrm{g} / \mathrm{mL}, \mathrm{p}$ $=0.395)($ Table 2$)$. 
Fig. 4 The graph shows elution of $0.6 \mathrm{~g}$ and $1.2 \mathrm{~g}$ amoxicillin and clavulanate mixed with $40 \mathrm{~g}$ customized bone cement with time. The solid line indicates amoxicillin in elution of $0.6 \mathrm{~g}$ amoxicillin and clavulanate; the long broken line indicates clavulanate in elution of $0.6 \mathrm{~g}$ amoxicillin and clavulanate; the broken line indicates amoxicillin in elution of $1.2 \mathrm{~g}$ amoxicillin and clavulanate; and the dotted line indicates clavulanate in elution of $1.2 \mathrm{~g}$ amoxicillin and clavulanate.

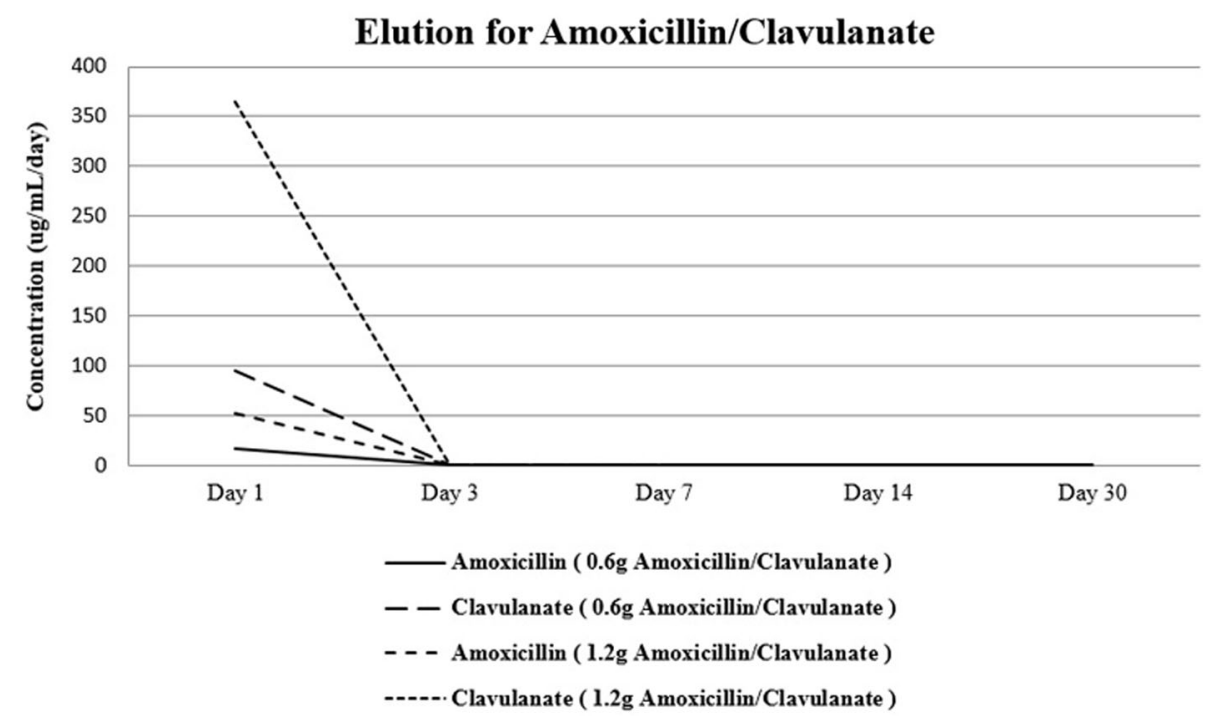

Table 1. Results of liquid chromatography-mass spectrometry in streptomycin or amoxicillin and clavulanate (ug/mL/day)*

\begin{tabular}{|c|c|c|c|c|c|}
\hline Drug & Day 1 & Day 3 & Day 7 & Day 14 & Day 30 \\
\hline Streptomycin (1 g) & $113.60 \pm 13.53$ & $12.56 \pm 4.10$ & $6.78 \pm 1.17$ & $4.58 \pm 1.68$ & $2.80 \pm 0.82$ \\
\hline Streptomycin (2 g) & $248.38 \pm 30.55$ & $29.70 \pm 6.19$ & $12.64 \pm 2.34$ & $9.10 \pm 2.74$ & $5.90 \pm 1.78$ \\
\hline \multicolumn{6}{|c|}{ Amoxicillin and clavulanate $(0.6 \mathrm{~g})$} \\
\hline Amoxicillin & $17.27 \pm 5.87$ & $0.29 \pm 0.18$ & ND & ND & ND \\
\hline Clavulanate & $95.01 \pm 46.13$ & ND & ND & ND & ND \\
\hline \multicolumn{6}{|c|}{ Amoxicillin and clavulanate (1.2 g) } \\
\hline Amoxicillin & $51.32 \pm 2.08$ & $0.79 \pm 0.24$ & $0.04 \pm 0.02$ & ND & ND \\
\hline Clavulanate & $365.19 \pm 39.72$ & ND & ND & ND & ND \\
\hline
\end{tabular}

* The results are presented as mean values measured from five discs; ND = not detectable.

Based on the mean MIC values obtained from the experiment (mean MIC values for streptomycin, amoxicillin and clavulanate, and streptomycin plus amoxicillin and clavulanate were $0.156,2.5$, and $0.313 \mathrm{ug} / \mathrm{mL}$ ), eluates of most antibiotic-loaded bone cement discs containing streptomycin had antimycobacterial activity for the entire study period, whereas regardless of dose, eluates of antibiotic-loaded bone cement discs containing amoxicillin and clavulanate only had antimycobacterial activity until Day 14 (Table 3). Eluates from antibiotic-loaded bone cement discs containing streptomycin and amoxicillin and clavulanate exhibited antimycobacterial activity for all times sampled. The antimycobacterial activities of streptomycin and amoxicillin and clavulanate decreased by approximately $10 \%$ a day until Day 7 . The antimycobacterial activity of eluates with $2 \mathrm{~g}$ streptomycin plus $1.2 \mathrm{~g}$ amoxicillin and clavulanate were higher than those of discs containing $1 \mathrm{~g}$ streptomycin plus $0.6 \mathrm{~g}$ amoxicillin and clavulanate until Day 3, without difference (Day 3, $1 \mathrm{~g}$ streptomycin plus $0.6 \mathrm{~g}$ amoxicillin and clavulanate: 17.5 $\pm 6.85 \mathrm{ug} / \mathrm{mL}, 2 \mathrm{~g}$ streptomycin plus $1.2 \mathrm{~g}$ amoxicillin and clavulanate: $32.5 \pm 16.77 \mathrm{ug} / \mathrm{mL}$, mean difference $=$ $-15.00 \mu \mathrm{g} / \mathrm{mL}, 95 \% \mathrm{CI}$ of the difference, lower $=-35.24$ $\mu \mathrm{g} / \mathrm{mL}$, upper $=5.27 \mu \mathrm{g} / \mathrm{mL} ; \mathrm{p}=0.109$ ) (Figs. 6, 7). After Day 7, however, values of the two combinations remained not different to Day 30 (Day 30, $1 \mathrm{~g}$ streptomycin plus 0.6 $\mathrm{g}$ amoxicillin and clavulanate: $0.88 \pm 0.34 \mathrm{ug} / \mathrm{mL}, 2 \mathrm{~g}$ streptomycin plus $1.2 \mathrm{~g}$ amoxicillin and clavulanate: 0.59 $\pm 0.94 \mathrm{ug} / \mathrm{mL}, 95 \% \mathrm{CI}$ of the difference, lower $-0.10 \mu \mathrm{g} /$ $\mathrm{mL}$, upper $0.68 \mu \mathrm{g} / \mathrm{mL} ; \mathrm{p}=0.107$ ) (Table 3 ).

\section{Discussion}

Antibiotic-loaded bone cement has been regarded as an important treatment modality for musculoskeletal tuberculosis, with published clinical evidence [1,32]. Since the availability of antibiotic-loaded bone cement varies depending on physical and chemical properties of the drug, it is necessary to search for a suitable drug that has proper physical properties after mixing $[7,18,19]$. In a previous study [20], we investigated the antibacterial activity and 


\section{Elution for Amoxicillin/Clavulanate}

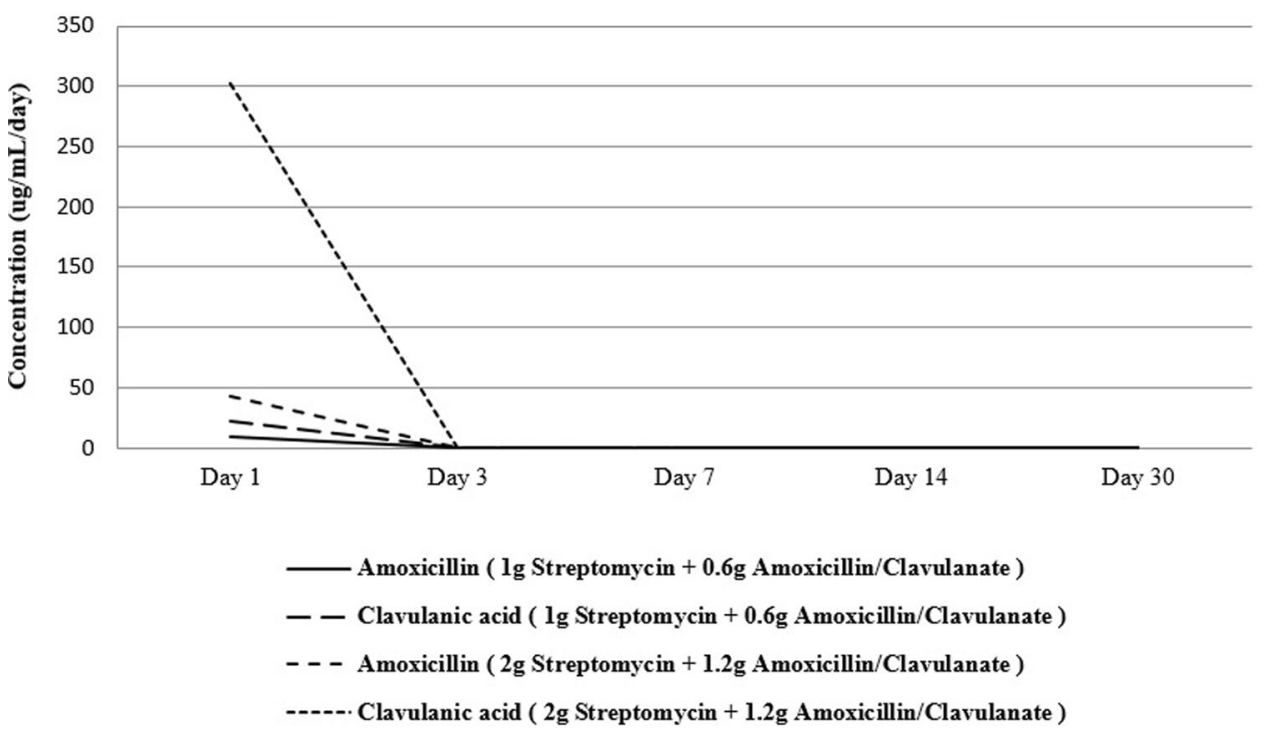

Fig. 5 The graph shows elution of $1 \mathrm{~g}$ streptomycin plus $0.6 \mathrm{~g}$ amoxicillin and clavulanate, and $2 \mathrm{~g}$ streptomycin plus $1.2 \mathrm{~g}$ amoxicillin and clavulanate mixed with $40 \mathrm{~g}$ customized bone cement with time. The solid line indicates amoxicillin in elution of $1 \mathrm{~g}$ streptomycin plus $0.6 \mathrm{~g}$ amoxicillin and clavulanate; the long broken line indicates clavulanate in elution of $1 \mathrm{~g}$ streptomycin plus $0.6 \mathrm{~g}$ amoxicillin and clavulanate; the broken line indicates amoxicillin in elution of $2 \mathrm{~g}$ streptomycin plus $1.2 \mathrm{~g}$ amoxicillin and clavulanate; and the dotted line indicates clavulanate in elution of $2 \mathrm{~g}$ streptomycin plus $1.2 \mathrm{~g}$ amoxicillin and clavulanate.

Table 2. Results of liquid chromatography-mass spectrometry in mixture of streptomycin and amoxicillin and clavulanate (ug/mL/day)

\begin{tabular}{|c|c|c|c|c|c|}
\hline Drug & Day 1 & Day 3 & Day 7 & Day 14 & Day 30 \\
\hline \multicolumn{6}{|c|}{ Streptomycin $(1 \mathrm{~g})+$ amoxicillin and clavulanate $(0.6 \mathrm{~g})$} \\
\hline Streptomycin & $122.66 \pm 15.13$ & $11.76 \pm 2.77$ & $5.96 \pm 1.07$ & $3.24 \pm 0.74$ & $1.86 \pm 0.58$ \\
\hline Amoxicillin & $9.37 \pm 2.36$ & $0.075 \pm 0.05$ & ND & ND & ND \\
\hline Clavulanate & $22.45 \pm 15.01$ & ND & ND & ND & ND \\
\hline \multicolumn{6}{|c|}{ Streptomycin $(2 \mathrm{~g})+$ amoxicillin and clavulanate $(1.2 \mathrm{~g})$} \\
\hline Streptomycin & $232.12 \pm 20.32$ & $27.76 \pm 11.57$ & $8.02 \pm 2.59$ & $4.06 \pm 0.95$ & $1.72 \pm 0.80$ \\
\hline Amoxicillin & $42.82 \pm 4.71$ & $0.42 \pm 0.15$ & ND & ND & ND \\
\hline Clavulanate & $302.67 \pm 51.35$ & ND & ND & ND & ND \\
\hline
\end{tabular}

* The results are presented as mean values measured from five discs; ND = not detectable.

Table 3. Measurement of antibacterial activity of eluents $(\mathrm{ug} / \mathrm{mL})^{\dagger}$

\begin{tabular}{|c|c|c|c|c|c|}
\hline Drug & Day 1 & Day 3 & Day 7 & Day 14 & Day 30 \\
\hline Streptomycin $1 \mathrm{~g}$ & $100.13 \pm 0.00 *$ & $7.50 \pm 2.79 *$ & $1.50 \pm 0.14^{*}$ & $1.13 \pm 0.28 *$ & $0.56 \pm 0.14^{*}$ \\
\hline Streptomycin $2 \mathrm{~g}$ & $180.23 \pm 44.78^{*}$ & $17.49 \pm 6.84^{*}$ & $2.50 \pm 0.86^{*}$ & $2.00 \pm 0.68 *$ & $0.88 \pm 0.34 *$ \\
\hline Amoxicillin and clavulanate $0.6 \mathrm{~g}$ & $112.10 \pm 43.96^{*}$ & $16.00 \pm 5.48^{*}$ & $4.67 \pm 0.75^{*}$ & $4.58 \pm 0.83 *$ & ND \\
\hline Amoxicillin and clavulanate $1.2 \mathrm{~g}$ & $160.26 \pm 0.00 *$ & $18.00 \pm 4.47 *$ & $9.00 \pm 2.24 *$ & $6.00 \pm 2.24 *$ & ND \\
\hline Streptomycin $1 \mathrm{~g}+$ amoxicillin and clavulanate $0.6 \mathrm{~g}$ & $200.32 \pm 0.00 *$ & $17.50 \pm 6.85^{*}$ & $3.00 \pm 0.28^{*}$ & $1.50 \pm 0.56^{*}$ & $0.88 \pm 0.34 *$ \\
\hline Streptomycin $2 \mathrm{~g}+$ amoxicillin and clavulanate $1.2 \mathrm{~g}$ & $400.64 \pm 0.00 *$ & $32.50 \pm 16.77^{*}$ & $3.00 \pm 0.28^{*}$ & $1.50 \pm 0.56^{*}$ & $0.58 \pm 0.09 *$ \\
\hline
\end{tabular}

${ }^{\dagger}$ Effluent could be decided effective for Mycobacterium tuberculosis when the concentration of the effluent was streptomycin $0.156 \mathrm{ug} / \mathrm{mL}$, amoxicillin and clavulanate $2.5 \mathrm{ug} / \mathrm{mL}$ and streptomycin + amoxicillin and clavulanate $0.313 \mathrm{mg} / \mathrm{L}$; *effective when the concentration of antibiotics was greater than the mean minimal inhibitory concentration value; ND $=$ not detectable. 
Fig. 6 The graph shows antimycobacterial activity of 1 $\mathrm{g}$ and $2 \mathrm{~g}$ streptomycin and 0.6 and $1.2 \mathrm{~g}$ amoxicillin and clavulanate mixed with $40 \mathrm{~g}$ customized bone cement with time. The solid line indicates antimycobacterial activity of $1 \mathrm{~g}$ streptomycin; the long broken line indicates antimycobacterial activity of $2 \mathrm{~g}$ streptomycin; the broken line indicates antimycobacterial activity of $0.6 \mathrm{~g}$ amoxicillin and clavulanate; and the dotted line indicates antimycobacterial activity of $1.2 \mathrm{~g}$ amoxicillin and clavulanate.

Fig. 7 The graph shows antimycobacterial activity of 1 $\mathrm{g}$ streptomycin plus $0.6 \mathrm{~g}$ amoxicillin and clavulanate, and $2 \mathrm{~g}$ streptomycin plus $1.2 \mathrm{~g}$ amoxicillin and clavulanate mixed with $40 \mathrm{~g}$ customized bone cement with time. The solid line indicates antimycobacterial activity of $1 \mathrm{~g}$ streptomycin plus $0.6 \mathrm{~g}$ amoxicillin and clavulanate and the broken line indicates antimycobacterial activity of $2 \mathrm{~g}$ streptomycin plus $1.2 \mathrm{~g}$ amoxicillin and clavulanate.
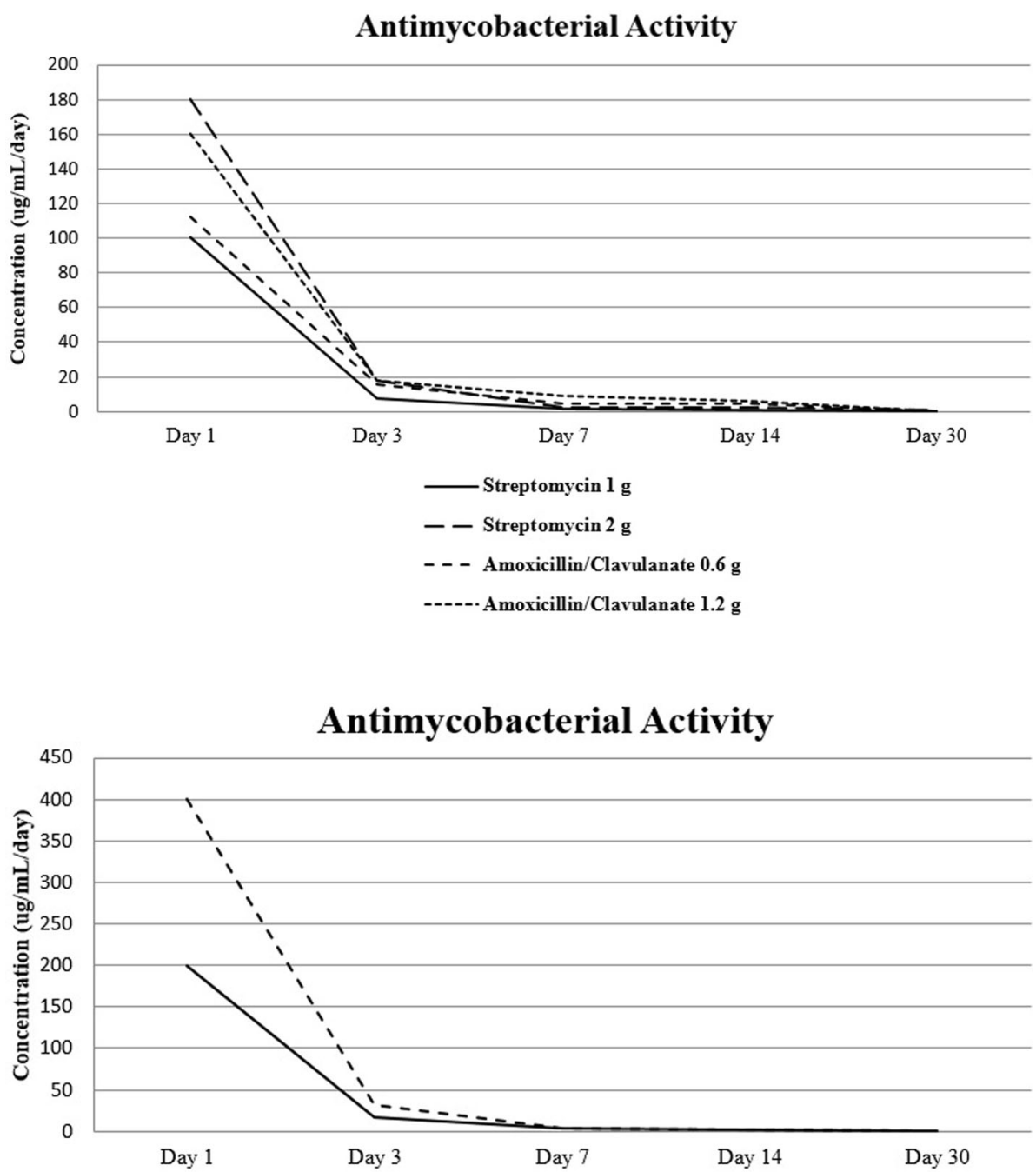

1 g Streptomycin + 0.6 g Amoxicillin/Clavulanate

- - $2 \mathrm{~g}$ Streptomycin $+1.2 \mathrm{~g}$ Amoxicillin/Clavulanate

elusion characteristics of bone cement by incorporating isoniazid and rifampicin, which are the first-line antituberculosis drugs. We found that rifampicin was unsuitable for bone cement owing to its delayed polymerization, and isoniazid was not available for practical use owing to oral formulations although it showed sufficient antimycobacterial activity for 30 days [20]. Therefore, we aimed to investigate the in vitro drug elution characteristics and antimycobacterial activity of eluate from bone cement loaded with streptomycin or Augmentin ${ }^{\circledR}$ (amoxicillin and clavulanate), which was made in powder form that can mix with bone cement.

There were several limitations to this investigation. First, we performed in vitro experiments, thus it is unclear if these findings will be valid in vivo. We exchanged the PBS every day, but this does not reflect the actual physiologic environment of the bone and joint combined. Unlike joints, it is known that the cumulative concentration of drug released increases with time and remains high in bone, therefore daily replacement of PBS may not reflect this environment [30]. In future studies, the elution test should be designed to mimic the bone and joint environment. Second, a strength test of the antibiotic-loaded bone cement was not performed, even though this is an essential factor to consider when antibiotic-loaded bone cement is to be used in operations like total knee or hip replacement for tuberculosis arthritis [7, 19, 37, 39], where the strength of the construct is important. Because the focus of our study 
was on musculoskeletal tuberculosis lesions such as intraosseous tuberculosis rather than infection after arthroplasty, we did not evaluate the strength of the antibiotic-loaded bone cement. Third, we did not investigate whether the effect of second-line drugs is able to be altered by the environment or mixing techniques. Numerous studies have shown that the effect of a drug may vary depending on the mixing method, environment, and kind of product, and these aspects need to be considered [4, 26, 30, 33-35]. Fourth, there were limitations in selecting medicines for mixing. Among second-line drugs of the aminoglycoside family, kanamycin and streptomycin are available in powder form. Although kanamycin and streptomycin bind the minor ribosomal subunit (30S) and inhibit protein synthesis, kanamycin is clinically preferred, as it is not susceptible to translocation inhibition and has a higher binding affinity than streptomycin [24]. However, we used streptomycin in this study, since kanamycin was not available in South Korea owing to supply issues at the time of our study. After choosing streptomycin based on the preliminary experimental results, we considered combining it with third-line drugs in the quinolone family, including levofloxacin or moxifloxacin. However, since these drugs were immiscible with the cement, they were not examined. Among fourth- and fifth-line antimicrobial drugs, we chose amoxicillin and clavulanate, in addition to synthesized antibiotic-loaded bone cement discs containing streptomycin and amoxicillin and clavulanate, based on preliminary results. It remains unclear how effective amoxicillin and clavulanate are for combating tuberculosis $[2,10]$. Although the effect of amoxicillin and clavulanate has been questioned, we reasoned that investigating the combined effects of amoxicillin and clavulanate and streptomycin would be meaningful, given the importance of multimodal treatment of musculoskeletal tuberculosis in overcoming resistance and minimizing treatment duration. Finally, only one kind of susceptible Mycobacterium tuberculosis was evaluated in this study. In several countries, diverse resistant strains including strains with extended drug resistance or total drug resistance have been reported, and it is challenging to achieve successful prevention and treatment when confronted with these resistant strains [3, 43, 47-49]. However, the prevalence of the susceptible mycobacterium strain remains considerable $[21,27,28,36]$, therefore our investigation of this susceptible strain is clinically relevant. Streptomycin release was maintained for the entire 30-day study period, while amoxicillin and clavulanate release was detected only for the first few days. A similar pattern was observed when streptomycin and amoxicillin and clavulanate were combined in discs. Amoxicillin and clavulanate no longer were detected after a week. Previous studies have shown differences in drug release attributable to interactions among drugs in elution tests $[23,38]$. However, our results indicate that the two drugs did not interfere with each other during the elution test. In addition, multiple factors are known to affect antibiotic elution from bone cement. Amin et al. [4] investigated the effect of quantity of liquid monomer and timing of antibiotic addition on the elution of vancomycin from bone cement. They found that delayed addition of antibiotic to high-dose-antibiotic bone cement increased vancomycin elution compared with the standard preparation, while incorporating additional liquid monomer decreased vancomycin elution from antibiotic cement. These findings suggest that, in our study, amoxicillin and clavulanate may be associated with a relatively delayed polymerization in the elution test that is maintained for a shorter duration than streptomycin since longer polymerization time makes it more likely to add antibiotic prematurely, based on the total manufacturing time. In addition, it takes more than 2 hours to complete the polymerization and it would not be suitable for practical use. Miller et al. [35] reported that the mixing method affected antimicrobial elution and mechanical properties of highdose antibiotic bone cement. Dough-phase mixing method led to greater antimicrobial elution compared with that of a hand-stirred method using a standard bowl and spatula or a bowl-mixed method with a mechanical mixing bowl, despite greater loss in compressive strength. Based on these results, such a method would offer a solution to overcome delayed polymerization by trying to add in the doughphase. Although this is a result of the characteristics and combination of the drugs, it would be possible to obtain more reliable results by controlling the conditions more precisely or applying various methods in further studies.

Stronger antimicrobial activities were observed for the mixed antibiotics than for antibiotics alone, indicating that they had a synergistic effect. Streptomycin had antimicrobial activity for the entire 30-day study period. Amoxicillin and clavulanate had antimicrobial activity for 14 days at $0.6 \mathrm{~g}$ and $1.2 \mathrm{~g}$, even though it was not detected in the elution test. Results of the experiment either showed no difference between the groups, or the difference was very small. When streptomycin and amoxicillin and clavulanate were combined, antimicrobial activity was maintained during the 30-day study period. It is unclear if amoxicillin and clavulanate had an antimicrobial effect for 30 days. However, as described above, the combination of streptomycin with amoxicillin and clavulanate could be useful during the early period of treatment of musculoskeletal tuberculosis, because amoxicillin and clavulanate exerted antimicrobial activity for approximately 2 weeks. Results of our previous study [20] are similar to the current findings, where most of the samples containing isoniazid showed antimycobacterial activity while the samples containing rifampicin showed 
antimycobacterial activity only on Day 1. However, antibacterial activity of the samples containing isoniazid and rifampicin was present up to Day 30 [20]. We did not find any previous studies that could directly explain these results. There have been several studies regarding the synergistic effect of multiple drugs against resistant strains, and it has been shown that interference with different molecular targets can be a more effective treatment method for multidrug resistant strains [6, 17, 22, 46]. Galvez-Lopez et al. [16] evaluated in vitro elution of 11 selected antibiotics from beads made with polymethylmethacrylate cement. However, in their experiment, amoxicillin and clavulanate showed minimal elution, with elute concentrations being almost undetectable at Day 4 and always below the MICs of susceptible organisms. They also stated that the inhibition zones of amoxicillin and clavulanate were small, suggesting a reduced elution of the drugs from cement beads in antibacterial activity. The causes of results from other studies [6, 16, 17, 22, 46] should be clarified through additional experiments in the future. In addition, streptomycin showed a synergistic effect when mixed with other drugs or materials for various strains and situations [5, 11, 41]. Therefore, in combination with other drugs, streptomycin is considered a useful candidate for antibiotic-loaded bone cement.

Streptomycin was detected in eluates from antibioticloaded bone cement discs during a prolonged time (30 days) and had antimicrobial effects for this entire period, whereas amoxicillin and clavulanate were detected in the eluates of antibiotic-loaded bone cement discs and showed antimicrobial activity only for a few days. Results of this study might contribute to the development of bone cementbased treatment methods that will be made by mixing multidrug agents. Various antibiotics at various doses and more mycobacterium strains should be studied in the future.

Acknowledgments We thank Hyun Soo Moon MD (Orthopaedic Surgery Department, Severance Hospital) for helping with data collection, and Changhun Park MS (Clinical Trials Center, Severance Hospital).

\section{References}

1. Aeng ES, Shalansky KF, Lau TT, Zalunardo N, Li G, Bowie WR, Duncan CP. Acute kidney injury with tobramycin-impregnated bone cement spacers in prosthetic joint infections. Ann Pharmacother. 2015;49:1207-1313.

2. Ahmed I, Jabeen K, Inayat R, Hasan R. Susceptibility testing of extensively drug-resistant and pre-extensively drug-resistant Mycobacterium tuberculosis against levofloxacin, linezolid, and amoxicillin-clavulanate. Antimicrob Agents Chemother. 2013;57: 2522-2525.

3. Ahmed MM, Velayati AA, Mohammed SH. Epidemiology of multidrug-resistant, extensively drug resistant, and totally drug resistant tuberculosis in Middle East countries. Int J Mycobacteriol. 2016;5:249-256.

4. Amin TJ, Lamping JW, Hendricks KJ, McIff TE. Increasing the elution of vancomycin from high-dose antibiotic-loaded bone cement: a novel preparation technique. J Bone Joint Surg Am. 2012;94:1946-1951.

5. Babalola CP, Patel KB, Nightingale CH, Nicolau DP. Synergistic activity of vancomycin and teicoplanin alone and in combination with streptomycin against Enterococcus faecalis strains with various vancomycin susceptibilities. Int J Antimicrob Agents. 2004;23:343-348.

6. Bhusal Y, Shiohira CM, Yamane N. Determination of in vitro synergy when three antimicrobial agents are combined against Mycobacterium tuberculosis. Int J Antimicrob Agents. 2005;26:292297.

7. Brock HS, Moodie PG, Hendricks KJ, McIff TE. Compression strength and porosity of single-antibiotic cement vacuum-mixed with vancomycin. J Arthroplasty. 2010;25:990-997.

8. Bryan WJ, Doherty JH Jr, Sculco TP. Tuberculosis in a rheumatoid patient: a case report. Clin Orthop Relat Res. 1982;171:206-208.

9. Campos OP. Bone and joint tuberculosis and its treatment. J Bone Joint Surg Am. 1955;37:937-966.

10. Chambers HF, Kocagoz T, Sipit T, Turner J, Hopewell PC. Activity of amoxicillin/clavulanatein patients with tuberculosis. Clin Infect Dis. 1998;26:874-877.

11. Chiodini RJ. Antimicrobial activity of rifabutin in combination with two and three other antimicrobial agents against strains of Mycobacterium paratuberculosis. $J$ Antimicrob Chemother. 1991;27:171-176.

12. Collins LA, Torrero MN, Franzblau SG. Green fluorescent protein reporter microplate assay for high-throughput screening of compounds against Mycobacterium tuberculosis. Antimicrob Agents Chemother. 1998;42:344-347.

13. Curtis JM, Sternhagen V, Batts D. Acute renal failure after placement of tobramycin-impregnated bone cement in an infected total knee arthroplasty. Pharmacotherapy. 2005;25:876-880.

14. Efstathopoulos N, Giamarellos-Bourboulis E, Kanellakopoulou K, Lazarettos I, Giannoudis P, Frangia K, Magnissalis E, Papadaki M, Nikolaou VS. Treatment of experimental osteomyelitis by methicillin resistant Staphylococcus aureus with bone cement system releasing grepafloxacin. Injury. 2008;39:1384-1390.

15. Friedlaender GE, Schiller AL. Case records of the Massachusetts General Hospital: weekly clinicopathological exercises: case 431983: an elderly man with progressive pain and swelling of the knee. N Engl J Med. 1983;309:1042-1049.

16. Galvez-Lopez R, Pena-Monje A, Antelo-Lorenzo R, GuardiaOlmedo J, Moliz J, Hernandez-Quero J, Parra-Ruiz J. Elution kinetics, antimicrobial activity, and mechanical properties of 11 different antibiotic loaded acrylic bone cement. Diagn Microbiol Infect Dis. 78:70-74.

17. Gonzalo X, Casali N, Broda A, Pardieu C, Drobniewski F. Combination of amikacin and doxycycline against multidrug-resistant and extensively drug-resistant tuberculosis. Int J Antimicrob Agents. 2015;45:406-412.

18. Goodell JA, Flick AB, Hebert JC, Howe JG. Preparation and release characteristics of tobramycin-impregnated polymethylmethacrylate beads. Am J Hosp Pharm. 1986;43:1454-1461.

19. Goss B, Lutton C, Weinrauch P, Jabur M, Gillett G, Crawford R. Elution and mechanical properties of antifungal bone cement. $J$ Arthroplasty. 2007;22:902-908.

20. Han CD, Oh T, Cho SN, Yang JH, Park KK. Isoniazid could be used for antibiotic-loaded bone cement for musculoskeletal tuberculosis: an in vitro study. Clin Orthop Relat Res. 2013;471:2400-2406. 
21. Ju HF, Wang XX, Li GL, Xie T, Zhao DF, Li SL, Li JX, Zhao H, $\mathrm{Mu}$ C. [Characteristics of Mycobacterium tuberculosis genotype and the relationship between Beijing genotype and drug-resistant phenotypes in Tianjin][in Chinese]. Zhonghua Liu Xing Bing Xue Za Zhi. 2011;32:116-119.

22. Kaushik A, Makkar N, Pandey P, Parrish N, Singh U, Lamichhane G. Carbapenems and Rifampin exhibit synergy against Mycobacterium tuberculosis and Mycobacterium abscessus. Antimicrob Agents Chemother. 2015;59:6561-6567.

23. Klekamp J, Dawson JM, Haas DW, DeBoer D, Christie M. The use of vancomycin and tobramycin in acrylic bone cement: biomechanical effects and elution kinetics for use in joint arthroplasty. J Arthroplasty. 1999;14:339-346.

24. Kotra LP, Haddad J, Mobashery S. Aminoglycosides: perspectives on mechanisms of action and resistance and strategies to counter resistance. Antimicrob Agents Chemother. 2000;44:32493256.

25. Leclere LE, Sechriest VF 2nd, Holley KG, Tsukayama DT. Tuberculous arthritis of the knee treated with two-stage total knee arthroplasty: a case report. J Bone Joint Surg Am. 2009;91:186-191.

26. Lee SH, Tai CL, Chen SY, Chang CH, Chang YH, Hsieh PH. Elution and mechanical strength of vancomycin-loaded bone cement: in vitro study of the influence of brand combination. PLoS One. 2016;11:e0166545.

27. Liu BB, Lu LP, Lu B, Wan KL, Yan Y. [Meta analysis on the correlation between Mycobacterium tuberculosis Beijing family strains and drug resistance][in Chinese]. Zhonghua Yu Fang $Y i$ Xиe Za Zhi. 2012;46:158-164.

28. Liu Z, Pang Y, Chen S, Wu B, He H, Pan A, Wang X. A first insight into the genetic diversity and drug susceptibility pattern of Mycobacterium tuberculosis complex in Zhejiang, China. Biomed Res Int. 2016;2016:8937539.

29. Lynch M, Esser MP, Shelley P, Wroblewski BM. Deep infection in Charnley low-friction arthroplasty. comparison of plain and gentamicin-loaded cement. J Bone Joint Surg Br. 1987;69:355-360.

30. Martinez-Moreno J, Mura C, Merino V, Nacher A, Climente M, Merino-Sanjuan M. Study of the influence of bone cement type and mixing method on the bioactivity and the elution kinetics of ciprofloxacin. J Arthroplasty. 2015;30:1243-1249.

31. Masri BA, Duncan CP, Beauchamp CP. Long-term elution of antibiotics from bone-cement: an in vivo study using the prosthesis of antibiotic-loaded acrylic cement (PROSTALAC) system. J Arthroplasty. 1998;13:331-338.

32. Masri BA, Duncan CP, Jewesson P, Ngui-Yen J, Smith J. Streptomycin-loaded bone cement in the treatment of tuberculous osteomyelitis: an adjunct to conventional therapy. Can J Surg. 1995;38:64-68.

33. McLaren RL, McLaren AC, Vernon BL. Generic tobramycin elutes from bone cement faster than proprietary tobramycin. Clin Orthop Relat Res. 2008;466:1372-1376.

34. Meyer J, Piller G, Spiegel CA, Hetzel S, Squire M. Vacuummixing significantly changes antibiotic elution characteristics of commercially available antibiotic-impregnated bone cements. $J$ Bone Joint Surg Am. 2011;93:2049-2056.

35. Miller R, McLaren A, Leon C, McLemore R. Mixing method affects elution and strength of high-dose ALBC: a pilot study. Clin Orthop Relat Res. 2012;470:2677-2683.
36. Mokrousov I. Mycobacterium tuberculosis phylogeography in the context of human migration and pathogen's pathobiology: insights from Beijing and Ural families. Tuberculosis (Edinb). 2015;95(suppl 1):S167-176.

37. Paz E, Sanz-Ruiz P, Abenojar J, Vaquero-Martin J, Forriol F, Del Real JC. Evaluation of elution and mechanical properties of highdose antibiotic-loaded bone cement: comparative "in vitro" study of the influence of vancomycin and cefazolin. $J$ Arthroplasty. 2015;30:1423-1429.

38. Penner MJ, Masri BA, Duncan CP. Elution characteristics of vancomycin and tobramycin combined in acrylic bone-cement. $J$ Arthroplasty. 1996;11:939-944.

39. Pithankuakul K, Samranvedhya W, Visutipol B, Rojviroj S. The effects of different mixing speeds on the elution and strength of high-dose antibiotic-loaded bone cement created with the handmixed technique. J Arthroplasty. 2015;30:858-863.

40. Qiu XS, Zheng X, Shi HF, Zhu YC, Guo X, Mao HJ, Xu GY, Chen YX. Antibiotic-impregnated cement spacer as definitive management for osteomyelitis. BMC Musculoskelet Disord. 2015; $16: 254$

41. Saavedra MJ, Borges A, Dias C, Aires A, Bennett RN, Rosa ES, Simoes M. Antimicrobial activity of phenolics and glucosinolate hydrolysis products and their synergy with streptomycin against pathogenic bacteria. Med Chem. 2010;6:174-183.

42. Su JY, Huang TL, Lin SY. Total knee arthroplasty in tuberculous arthritis. Clin Orthop Relat Res. 1996;323:181-187.

43. Velayati AA, Masjedi MR, Farnia P, Tabarsi P, Ghanavi J, Ziazarifi AH, Hoffner SE. Emergence of new forms of totally drugresistant tuberculosis bacilli: super extensively drug-resistant tuberculosis or totally drug-resistant strains in Iran. Chest. 2009; 136:420-425.

44. Wilkinson MC. Synovectomy and curettage in the treatment of tuberculosis of joints. J Bone Joint Surg Br. 1953;35:209-223.

45. Yan AY, Faro FD, Schon LC. Using cement plugs in soft tissue infection and osteomyelitis. Orthopedics. 2014;37:32-36.

46. Zhao W, Zheng M, Wang B, Mu X, Li P, Fu L, Liu S, Guo Z. Interactions of linezolid and second-line anti-tuberculosis agents against multidrug-resistant Mycobacterium tuberculosis in vitro and in vivo. Int $J$ Infect Dis. 2016;52:23-28.

47. Zignol M, Dara M, Dean AS, Falzon D, Dadu A, Kremer K, Hoffmann H, Hoffner S, Floyd K. Drug-resistant tuberculosis in the WHO European region: an analysis of surveillance data. Drug Resist Updat. 2013;16:108-115.

48. Zignol M, Dean AS, Alikhanova N, Andres S, Cabibbe AM, Cirillo DM, Dadu A, Dreyer A, Driesen M, Gilpin C, Hasan R, Hasan Z, Hoffner S, Husain A, Hussain A, Ismail N, Kamal M, Mansjo M, Mvusi L, Niemann S, Omar SV, Qadeer E, Rigouts L, Ruesch-Gerdes S, Schito M, Seyfaddinova M, Skrahina A, Tahseen S, Wells WA, Mukadi YD, Kimerling M, Floyd K, Weyer K. Raviglione MC. Population-based resistance of mycobacterium tuberculosis isolates to pyrazinamide and fluoroquinolones: results from a multicountry surveillance project. Lancet Infect Dis. 2016;16:1185-1192.

49. Zignol M, van Gemert W, Falzon D, Sismanidis C, Glaziou P, Floyd K. Raviglione M. Surveillance of anti-tuberculosis drug resistance in the world: an updated analysis, 2007-2010. Bull World Health Organ. 2012;90:111-119d. 